\title{
Causative Pathogens in Endophthalmitis after Intravitreal Injection of Anti-vascular Endothelial Growth Factor Agents
}

\author{
Cecilia P. Labardini, M.D. ${ }^{1}$ and Eytan Z. Blumenthal, M.D. ${ }^{1,2 *}$ \\ ${ }^{\prime}$ Department of Ophthalmology, Rambam Health Care Campus, Haifa, Israel; and ${ }^{2}$ The Ruth $\Xi^{2}$ Bruce \\ Rappaport Faculty of Medicine, Technion-Israel Institute of Technology, Haifa, Israel
}

\begin{abstract}
Intravitreal injection of anti-vascular endothelial growth factor is currently the preferred treatment for several posterior segment diseases, including age-related macular degeneration and diabetic retinopathy, as well as macular edema and retinal vein occlusion. As an invasive procedure it involves risks. The most significant risk is infectious endophthalmitis, a sight-threatening and even a globe-threatening acute fulminant condition. Most common pathogens include Streptococcus and Staphylococcus species, surprisingly originating from the patient's, surgeon's, or nurse's mouth. Infectious endophthalmitis may have devastating and irreversible effect, with Streptococcus-induced cases having the worst visual outcome. It is therefore crucial for clinicians to promptly recognize and treat such conditions, and, far more important, to put in place protective and preventive measures against this rare, but sight-threatening complication. To that end, this paper describes the most common pathogens causing endophthalmitis after IVI of anti-VEGF, and defines their source, to aid the physician in developing strategies to prevent this catastrophic infection.
\end{abstract}

KEY WORDS: Anti-VEGF, bacterial infection, endophthalmitis, intravitreal injection

Abbreviations: CFU, colony-forming units; IVI, intravitreal injection; VA, visual acuity; VEGF, vascular endothelial growth factor.

Citation: Labardini CP, Blumenthal EZ. Causative Pathogens in Endophthalmitis after Intravitreal Injection of Antivascular Endothelial Growth Factor Agents. Rambam Maimonides Med J 2018;9 (4):eoo32. Review.

doi:10.5041/RMMJ.10348

Copyright: (C) 2018 Labardini and Blumenthal. This is an open-access article. All its content, except where otherwise noted, is distributed under the terms of the Creative Commons Attribution License

(http://creativecommons.org/licenses/by/3.o), which permits unrestricted use, distribution, and reproduction in any medium, provided the original work is properly cited.

Conflict of interest: No potential conflict of interest relevant to this article was reported.

* To whom correspondence should be addressed. E-mail: e_blumenthal@rambam.health.gov.il 


\section{INTRODUCTION}

Intravitreal injection (IVI) of anti-vascular endothelial growth factor (VEGF) has revolutionized in the past decade, and is currently the preferred treatment for several posterior segment diseases, among them age-related macular degeneration, diabetic retinopathy, as well as macular edema and retinal vein occlusion. ${ }^{1,2}$ Clinical trials have repeatedly and consistently demonstrated visual as well as anatomic improvement following therapy with anti-VEGF in the aforementioned diseases. 3 Injections are usually administered at 1-2 monthly intervals for a period lasting between several months and up to many years. 4 The use of these medications has increased considerably in the last 5 years, ${ }^{1}$ becoming the most commonly performed ophthalmic procedure in the United States.5,6

As in every invasive procedure, a risk of complications exists with IVI procedures, the most important one being endophthalmitis, which carries a devastating outcome.1,7,8 With the increasing number of IVI, the number of cases of endophthalmitis has also grown. 4 Identifying the infectious agents involved in endophthalmitis after IVI is essential to provide the appropriate empiric antibiotic treatment.

Endophthalmitis is an intraocular inflammatory response to a bacterial or fungal infection inside the eye. Such infections start in the aqueous humor, the vitreous body, or both.4,9 Endophthalmitis is justifiably one of the most serious and urgent emergencies encountered in ophthalmic practice. ${ }^{10}$ Clinical signs and symptoms include decreased vision, mild to moderate pain, a red eye, anterior chamber inflammation, and vitritis. ${ }^{11}$

Even though the incidence of endophthalmitis after anti-VEGF injections is very low ${ }^{4,11}$ (rates range from $0.038 \%$ to $0.065 \%$, which translates to 1 in $2,632$ to 1 in 1,538$), 8$ the visual prognosis is often poor, depending primarily on the time to treatment, the virulence of the infecting pathogen, and the treatment chosen. Prompt diagnosis and treatment can save eyes and achieve satisfactory visual results. ${ }^{10}$

This article describes the most common pathogens that cause endophthalmitis after IVI of antiVEGF and defines their source, in order to provide strategies for preventing this catastrophic infection.

\section{PATHOGENIC AGENTS}

Vitreous cultures are reported positive in $45 \%-60 \%$ of the cases of infectious endophthalmitis after anti-
VEGF IVI, ${ }^{1,4,11}$ Gram-positive bacteria being responsible for over $95 \%$ of culture-positive cases. 4

The most commonly isolated organisms in endophthalmitis following IVI are Staphylococcus (38\%-60\%) and Streptococcus species (25\%$33 \%)^{1,11}$ Other less frequent causative organisms include Bacillus and Haemophilus species (Table 1). ${ }^{1}$

Table 1. Most Commonly Isolated Organisms in Endophthalmitis Following IVI.

\begin{tabular}{|l|c|}
\hline Organism & $\begin{array}{c}\text { Percent Found in } \\
\text { Endophthalmitis }\end{array}$ \\
\hline Staphylococcus species & $38 \%-60 \%^{1,11}$ \\
Streptococcus species & $25 \%-33 \%^{1,11}$ \\
Bacillus species & $<10 \%^{1}$ \\
Haemophilus species & $<10 \%^{1}$ \\
\hline
\end{tabular}

Streptococcus species are roughly $30 \%$ more frequent in endophthalmitis after anti-VEGF IVI than following incisional ocular surgery, compared to coagulase-negative Staphylococcus species, less frequently seen after IVI than after incisional surgery. ${ }^{1}$

There are no significant differences reported in endophthalmitis rates after the administration of either bevacizumab, ranibizumab, or aflibercept (anti-VEGF agents). ${ }^{11}$

An increased prevalence of oral flora-associated organisms, in particular Streptococcus species, in endophthalmitis following IVI compared to other penetrating intraocular procedures was found in multiple studies. ${ }^{2,8,12-14}$ These organisms are thought to originate from the physician, the assistant nurse, and/or the patient, secondary to speaking during the IVI procedure..$^{15-17}$

Some studies found that wearing facemasks, ${ }^{16,18,19}$ and/or adopting a no-talking policy, reduced the speech-related bacterial contamination of the surgical field. ${ }^{8,12-17}$

One potential advantage of the use of facemasks is that it allows the patient, the physician, and the nurse assistant to speak during the procedure without the inherent risk involved. Of note, throughout the IVI procedure speaking is needed/encouraged to allow for the "pre-injection timeout," and to verbally redirect the patient's eye movements as needed, as well as to ease and comfort the patient during this potentially stressful procedure. ${ }^{20}$ 
Having said that, the use of facemasks during the IVI procedure is currently not considered to be part of standard of care, but, considering the increased risk of endophthalmitis resulting from oral species following IVI, its use, in addition to refraining from speaking and maintaining sterile conditions during the IVI procedure, was recommended. ${ }^{21}$

A study performed by Garg et al. ${ }^{2}$ demonstrated that a strict no-talking policy during IVI reduced the incidence of endophthalmitis post injection, presumably via a reduction in the oral cavity-associated spread of such pathogens. In this study two groups were compared. The first was a retrospectively examined group, in which a no-talking policy was not required: $0.057 \%$ of the cases $(27 / 47,155$ eyes) after IVI presented with endophthalmitis, of which $0.019 \%$ (9 eyes) had positive cultures. Of these positive culture endophthalmitis cases, $78 \%$ (0.015\% of the total cases reviewed, 7 eyes) grew oral cavity flora including viridans streptococci, Streptococcus mitis, and Lactobacillus. Of the above, Streptococcus species represent more than $40 \%$ of oral cavity flora in adults, ${ }^{22}$ while Lactobacillus is often present in oral, vaginal, and gastrointestinal mucosa. ${ }^{23}$ The results were dramatically different when prospectively a no-talking policy was applied. In this arm of the study, containing 82,658 patients, only $0.024 \%$ of the cases (19 eyes) presented with endophthalmitis, $0.01 \%$ ( 8 eyes) had positive cultures, of which only $29 \%$ ( 2 eyes, $0.002 \%$ of the entire group) grew oral cavity bacteria, including a single case that cultured positive for Streptococcus salivarius/vestibularis, and one case in which Streptococcus sanguinis was isolated. ${ }^{2}$

The occurrence of culture-positive endophthalmitis cases while a strict no-talking policy was used illustrates that although a no-talking strategy is very effective, it will not eradicate all cases. ${ }^{2}$ Oral pathogens represent roughly $7 \%$ of isolates found when the normal human conjunctival flora is swabbed and cultured, ${ }^{24-27}$ hence this may reflect endophthalmitis independent of oral dispersion. ${ }^{2}$

Doshi et al. ${ }^{16}$ compared the no-talking policy to wearing a surgical mask via an interesting study design in which surgeons were asked to talk in front of blood agar plates. The surgeons were divided into four groups: the first did not wear a surgical mask; the second wore a surgical mask; the third did not wear a mask, and the culture plates were pre-exposed to $5 \%$ povidone-iodine; and the fourth one did not wear a mask, and a strict no-talking policy was implemented. The results showed bacterial growth as colony-forming units (CFU) per subject in each of the groups, respectively, as follows: the first group 8.8 CFU, the second group 1.1 CFU, the third group o.1 CFU, and the fourth group 2.4 CFU. Statistically significant difference was found between all four groups, except for a non-significant difference $(P=$ 0.115 ) between groups 2 and 4. This study suggests that both wearing a surgical mask and applying a no-talking policy significantly reduced the risk of endophthalmitis. These recommendations should be applied in addition to the already standard use of topical povidone-iodine prior to the injection. ${ }^{16}$

\section{Visual Prognosis}

Endophthalmitis following IVI may have devastating long-term visual consequences. ${ }^{1}$

Endophthalmitis after intravitreal anti-VEGF injections, in which Streptococcus species are isolated, lead to poorer visual outcomes when compared to endophthalmitis caused by coagulase-negative Staphylococcus bacteria, as well as to culture-negative endophthalmitis. As many as $94 \%$ of endophthalmitis patients with Streptococcus-positive cultures had a final visual acuity (VA) of 20/400 (6/120) or worse. They were 125 times more likely to reach a low VA as compared to patients with culturenegative endophthalmitis, and 111 times more likely as compared to patients with coagulase-negative Staphylococcus endophthalmitis. There is no significant difference between culture-negative endophthalmitis and coagulase-negative Staphylococcus regarding visual outcomes, ${ }^{1}$ but the former tends to be associated with a less severe clinical course. ${ }^{11}$

\section{Culture-negative Endophthalmitis}

Lack of growth of any pathogen may correspond to either a small bacterial load or suboptimal swabbing (both of which resulting in an inability to isolate and grow the pathogenic bacteria in culture), or to a truly non-infectious inflammatory process. ${ }^{11}$

While fibrin and the appearance of a hypopyon (the accumulation in the anterior chamber of white blood cells) are primarily associated with infectious cases, especially Gram-positive pathogens, ${ }^{11}$ noninfectious inflammation cases may also occasionally present with a hypopyon. ${ }^{28,29}$ Additionally, the onset of presentation post-IVI, the magnitude of vision decrease, and the amount of pain all tend to be milder in non-infectious cases, but are not diagnostic as they have been reported in both infectious ${ }^{30}$ as well 
as non-infectious cases. ${ }^{28,31}$ Hence, these findings are not reliable in differentiating true infections from sterile inflammation. ${ }^{11}$

\section{Aflibercept-related Inflammation}

It is likely that at least some of the culture-negative endophthalmitis cases in fact represent sterile aflibercept-related inflammation. ${ }^{28,29}$ The American Society of Retina Specialists Therapeutic Surveillance Committee previously reported 15 cases of what appeared to be a sterile inflammation following intravitreal aflibercept (during the first 3 months after approval) originating from five separate drug lots. During this time 30,000 injections were applied, reflecting a sterile inflammation rate of $0.05 \%$ (15 eyes). From the cases reported, all but one case presented within a period of 3 days following injection. Pain was reported by $60 \%$, while redness appeared in $40 \%$ of this group. ${ }^{29}$

Other studies reported cases compatible with noninfectious inflammation after aflibercept IVI, presenting symptoms within 1-3 days of the injection, with decreased or blurred vision and vitritis. Other symptoms such as pain and conjunctival injection were less frequent, and only few patients presented with a hypopyon. ${ }^{11,28}$ Those who present with what appears to be an aflibercept-related sterile inflammatory process have a good visual acuity prognosis following a time-limited course lasting $7-73$ days. ${ }^{11}$

The differentiation between infectious and noninfectious endophthalmitis is extremely challenging; hence, injected individuals in whom a non-infectious endophthalmitis is suspected must be followed up very closely for the appearance of signs of improvement, or deterioration, when treated with topical steroids for the presumed diagnosis of a sterile inflammation. ${ }^{11}$

\section{PREVENTION}

\section{Povidone-iodine}

Evidence has shown that topical povidone-iodine is the most effective protective-prophylactic measure aimed at reducing the incidence of bacterial infection after IVI.1,11,16,32

A retrospective case-control series performed by Levinson et al. demonstrated that the application of povidone-iodine after placing the lid speculum decreases the incidence of endophthalmitis after IVI, due to the prevention of contact between the eyelid and the injection site. 33

\section{Topical Antibiotics}

Several studies consistently showed that the prophylactic application of topical antibiotics before as well as after the injection did not have any apparent beneficial effect on the rates of endophthalmitis post-IVI, ${ }^{32,34-36}$ and, surprising as it might seem, it may even increase the risk for endophthalmitis. ${ }^{37,38}$ This might be because multiple exposures to topical antibiotic drops alter the ocular flora and increase the presence of more virulent organisms (and perhaps assist in the appearance of resistant ones) on the ocular surface. ${ }^{26,38}$ These findings, in addition to the benefit of reduced cost, led the standard of care surrounding IVI to eliminate topical antibiotic prophylaxis. ${ }^{37}$

\section{Hand Antisepsis}

Performing hand antisepsis at the beginning of all invasive procedures is important in order to reduce any bacterial load. 39 When performing a session of injections, the hand antisepsis should initiate by washing them with soap or aqueous scrub to eliminate dirt and the usual bacterial load. Between each injection in the same session, alcohol-based rubs are ideal, due to their faster action and less skin irritation. 40

\section{Gloves}

Sterile gloves are required for performing aseptic procedures..$^{4}$ Even though studies comparing the use of sterile and non-sterile gloves during IVI application have not yet being performed, this procedure should be considered an aseptic one, due to the fact that it involves penetration into an immune-privileged organ. ${ }^{40}$

\section{OTHER CONSIDERATIONS}

The utilization of lidocaine gel (rather than in the form of drops) to anesthetize the surface of the eye, prior to the use of povidone-iodine antisepsis, was not shown to significantly alter post-IVI endophthalmitis rates. ${ }^{42}$ Similarly, the facility where the injection takes place (an operating room versus an outpatient clinic) was not shown to have any significant effect on the incidence of endophthalmitis. ${ }^{37}$

\section{CONCLUSIONS}

Endophthalmitis after anti-VEGF IVI represents a grave visual outcome, so all efforts to reduce its incidence are justified. As IVI injections are carried out ever more frequently, it is imperative to understand 
the pathogenic process and identify underlying risk factors, and to study the etiological agents and factors involved, in order to properly prevent, or identify and treat, this vision-threatening condition. The most common causative agents are Streptococcus and Staphylococcus species due to an oral flora translocation from the patient, the surgeon, and/or the nurse assistant. In addition, one should always take into account the possibility of a sterile inflammation as well as other contamination pathways. Strict prevention, care, and follow-up after the procedure may help reduce post-IVI endophthalmitis rates.

\section{REFERENCES}

1. Fileta JB, Scott IU, Flynn HW Jr. Meta-analysis of infectious endophthalmitis after intravitreal injection of anti-vascular endothelial growth factor agents. Ophthalmic Surg Lasers Imaging Retina 2014;45: 143-9. $\underline{\text { Crossref }}$

2. Garg SJ, Dollin M, Hsu J, Storey P, Vander JF. Effect of a strict 'no-talking' policy during intravitreal injection on post-injection endophthalmitis. Ophthalmic Surg Lasers Imaging Retina 2015;46:1028-34. Crossref

3. Moshfeghi AA, Rosenfeld PJ, Flynn HW Jr, et al. Endophthalmitis after intravitreal vascular [corrected] endothelial growth factor antagonists: a six-year experience at a university referral center. Retina 2011;31:662-8. Crossref

4. Durand ML. Endophthalmitis. Clin Microbiol Infect 2013;19:227-34.

5. Campbell RJ, Bronskill SE, Bell CM, Paterson JM, Whitehead M, Gill SS. Rapid expansion of intravitreal drug injection procedures, 2000 to 2008: a population-based analysis. Arch Ophthalmol 2010; 128:359-62. Crossref

6. Williams GA. IVT injections: health policy implications. Review of Ophthalmology 2014; June. Available at: http://bit.ly/2uo84kl (accessed July 2, 2018).

7. Shah CP, Garg SJ, Vander JF, Brown GC, Kaiser RS, Haller JA; Post-Injection Endophthalmitis (PIE) Study Team. Outcomes and risk factors associated with endophthalmitis after intravitreal injection of anti-vascular endothelial growth factor agents. Ophthalmology 2011;118:2028-34. Crossref

8. McCannell CA. Meta-analysis of endophthalmitis after intravitreal injection of anti-vascular endothelial growth factor agents: causative organisms and possible prevention strategies. Retina 2011;31:65461. $\underline{\text { Crossref }}$
9. O'Callaghan RJ. The pathogenesis of Staphylococcus aureus eye infections. Pathogens 2018;7:9. Crossref

10. Peyman GA, Bassili SS. A practical guideline for management of endophthalmitis. Ophthalmic Surg 1995;26:294-303.

11. Gregori NZ, Flynn HW, Schwartz SG, et al. Current infectious endophthalmitis rates after intravitreal injections of anti-vascular endothelial growth factor agents and outcomes of treatment. Ophthalmic Surg Lasers Imaging Retina 2015;46:643-8. Crossref

12. Simunovic MP, Rush RB, Hunyor AP, Chang AA. Endophthalmitis following intravitreal injection versus endophthalmitis following cataract surgery: clinical features, causative organisms and post-treatment outcomes. Br J Ophthalmol 2012;96:862-6. Crossref

13. Chen E, Lin MY, Cox J, Brown DM. Endophthalmitis after intravitreal injection: the importance of viridans streptococci. Retina 2011;31:1525-33. Crossref

14. Garg SJ, Dollin M, Storey P, et al. Microbial spectrum and outcomes of endophthalmitis after intravitreal injection versus pars plana vitrectomy. Retina 2016; 36:351-9. Crossref

15. Wen JC, McCannel CA, Mochon AB, Garner OB. Bacterial dispersal associated with speech in the setting of intravitreous injections. Arch Ophthalmol 2011; 129:1551-4. Crossref

16. Doshi RR, Leng T, Fung AE. Reducing oral flora contamination of intravitreal injections with face mask or silence. Retina 2012;32:473-6. Crossref

17. Friedman DA, Lindquist TP, Mason JO III, McGwin G. Needle contamination in the setting of intravitreal injections. Retina 2014;34:929-34. Crossref

18. Shimada H, Hattori T, Mori R, Nakashizuka H, Fujita $\mathrm{K}$, Yuzawa M. Minimizing the endophthalmitis rate following intravitreal injections using $0.25 \%$ povidone-iodine irrigation and surgical mask. Graefes Arch Clin Exp Ophthalmol 2013;251:1885-90. Crossref

19. Brynskov T, Kemp H, Sørensen TL. No cases of endophthalmitis after 20,293 intravitreal injections in an operating room setting. Retina 2014;34:951-7. Crossref

20. Schachat AP, Rosenfeld PJ, Liesegang TJ, Stewart MW. Endophthalmitis is not a "never event." Ophthalmology 2012;119:1507-8. $\underline{\text { Crossref }}$

21. Schimel AM, Scott IU, Flynn HW Jr. Endophthalmitis after intravitreal injections: should the use of face masks be the standard of care? Arch Ophthalmol 2011;129:1607-9. Crossref

22. Gordon DF, Jong BB. Indigenous flora from human saliva. Appl Microbiol 1968;16:428-9. 
23. Ahrne S, Nobaek S, Jeppsson B, Adlerberth I, Wold AE, Molin G. The normal Lactobacillus flora of healthy human rectal and oral mucosa. J Appl Microbiol 1998;85:88-94.

24. Moss JM, Sanislo SR, Ta CN. A prospective randomized evaluation of topical gatifloxacin on conjunctival flora in patients undergoing intravitreal injections. Ophthalmology 2009;116:1498-501. Crossref

25. Milder E, Vander J, Shah C, Garg S. Changes in antibiotic resistance patterns of conjunctival flora due to repeated use of topical antibiotics after intravitreal injection. Ophthalmology 2012;119:1420-4. Crossref

26. Yin VT, Weisbrod DJ, Eng KT, et al. Antibiotic resistance of ocular surface flora with repeated use of a topical antibiotic after intravitreal injection. JAMA Ophthalmol 2013;131:456-61. $\underline{\text { Crossref }}$

27. Kim SJ, Toma HS, Midha NK, Cherney EF, Recchia FM, Doherty TJ. Antibiotic resistance of conjunctiva and nasopharynx evaluation study: a prospective study of patients undergoing intravitreal injections. Ophthalmology 2010;117:2372-8. Crossref

28. Goldberg RA, Shah CP, Wiegand TW, Heier JS. Noninfectious inflammation after intravitreal injection of aflibercept: clinical characteristics and visual outcomes. Am J Ophthalmol 2014;158:733-7. Crossref

29. Hahn P, Kim JE, Stinnett S, et al. Aflibercept-related sterile inflammation. Ophthalmology 2013;120:1100101.e1-5. Crossref

30. Moshfeghi AA. Endophthalmitis following intravitreal anti-vascular endothelial growth factor injections for neovascular age-related macular degeneration. Semin Ophthalmol 2011;26:139-48. $\underline{\text { Crossref }}$

31. Kay CN, Tarantola RM, Gehrs KM, et al. Uveitis following intravitreal bevacizumab: a non-infectious cluster. Ophthalmic Surg Lasers Imaging 2011; 42:292-6. $\underline{\text { Crossref }}$

32. Doshi RR, Leng T, Fung AE. Povidone-iodine before lidocaine gel anesthesia achieves surface antisepsis. Ophthalmic Surg Lasers Imaging 2011;42:346-9. Crossref

33. Levinson J, Garfinkel R, Berinstein DM, Flory M, Spellman FA. Timing of povidone-iodine application to reduce the risk of endophthalmitis after intravitreal injections. Presented at American Society of Retina Specialists Annual Meeting, August 11-15, 2017, Boston, Massachusetts. Ophthalmol Retina 2017 August 31. $\underline{\text { Crossref }}$

34. Bhavsar AR, Stockdale CR, Ferris FL 3rd, Brucker AJ, Bressler NM, Glassman AR; Diabetic Retinopathy Clinical Research Network. Update on risk of endophthalmitis after intravitreal drug injections and potential impact of elimination of topical antibiotics. Arch Ophthalmol 2012;130:809-10. $\underline{\text { Crossref }}$

35. Bhavsar AR, Googe JM Jr, Stockdale CR, et al. Risk of endophthalmitis after intravitreal drug injection when topical antibiotics are not required: the diabetic retinopathy clinical research network laserranibizumab-triamcinoloneclinical trials. Arch Ophthalmol 2009;127:1581-3. Crossref

36. Cheung CS, Wong AW, Lui A, Kertes PJ, Devenyi RG, Lam WC. Incidence of endophthalmitis and use of antibiotic prophylaxis after intravitreal injections. Ophthalmology 2012;119:1609-14. Crossref

37. Bande MF, Mansilla R, Pata MP, et al. Intravitreal injections of anti-VEGF agents and antibiotic prophylaxis for endophthalmitis: a systematic review and meta-analysis. Sci Rep 2017;7:18088. Crossref

38. Menchini F, Toneatto G, Miele A, Donati S, Paolo L, Virgili G. Antibiotic prophylaxis for preventing endophthalmitis after intravitreal injection: a systematic review. Eye 2018 June 11. [Epub ahead of print]. $\underline{\text { Crossref }}$

39. Tanner J, Swarbrook S, Stuart J. Surgical hand antisepsis to reduce surgical site infection. Cochrane Database Syst Rev 2008;(1):CDoo4288. Crossref

40. Merani R, Hunyor A. Endophthalmitis following intravitreal anti-vascular endothelial growth factor (VEGF) injection: a comprehensive review. Int $\mathrm{J}$ Retin Vitr 2015;1:9. $\underline{\text { Crossref }}$

41. Flores A. Sterile versus non-sterile glove use and aseptic technique. Nurs Stand 2008;23:35-9. Crossref

42. Lad EM, Maltenfort MG, Leng T. Effect of lidocaine gel anesthesia on endophthalmitis rates following intravitreal injection. Ophthalmic Surg Lasers Imaging 2012;43:115-20. $\underline{\text { Crossref }}$ 